\title{
ERRATUM
}

\section{Erratum to: 24-h Efficacy of Glaucoma Treatment Options}

Anastasios G. P. Konstas · Luciano Quaranta - Banu Bozkurt •

Andreas Katsanos · Julian Garcia-Feijoo - Luca Rossetti •

Tarek Shaarawy $\cdot$ Norbert Pfeiffer $\cdot$ Stefano Miglior

Published online: March 28, 2016

(C) The Author(s) 2016. This article is published with open access at Springerlink.com

Erratum to: Adv Ther

DOI 10.1007/s12325-016-0302-0

The family name of one of the co-authors, Julian Garcia-Feijoo, was incorrect in the original publication. The correct family name should be Garcia-Feijoo.

The original article has been updated accordingly.

The online version of the original article can be found under doi:10.1007/s12325-016-0302-0.

A. G. P. Konstas $(\bowtie)$

1st University Department of Ophthalmology,

Aristotle University of Thessaloniki, Thessaloniki,

Greece

e-mail: konstas@med.auth.gr

A. G. P. Konstas

3rd University Department of Ophthalmology,

Aristotle University of Thessaloniki, Thessaloniki,

Greece

L. Quaranta

Glaucoma Unit, University of Brescia, Brescia, Italy

B. Bozkurt

Department of Ophthalmology, Selcuk University,

Konya, Turkey

\section{A. Katsanos}

Department of Ophthalmology, University of

Ioannina, Ioannina, Greece
Open Access. This article is distributed under the terms of the Creative Commons AttributionNonCommercial 4.0 International License (http://creativecommons.org/licenses/by-nc/4. $0 /$ ), which permits any noncommercial use, distribution, and reproduction in any medium, provided you give appropriate credit to the original author(s) and the source, provide a link to the Creative Commons license, and indicate if changes were made.

J. Garcia-Feijoo

University of Madrid, Madrid, Spain

L. Rossetti

Eye Clinic, San Paolo Hospital, University of Milan, Milan, Italy

T. Shaarawy

Glaucoma Sector, University of Geneva, Geneva, Switzerland

N. Pfeiffer

University of Mainz, Mainz, Germany

S. Miglior

Department of Ophthalmology, University Bicocca of Milan, Milan, Italy 